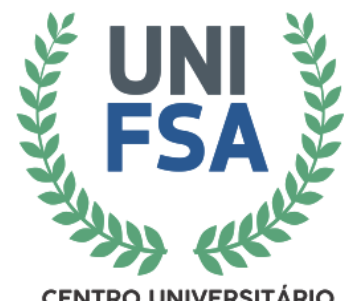

CENTRO UNIVERSITÁRIO SANTO ACOSTINHO

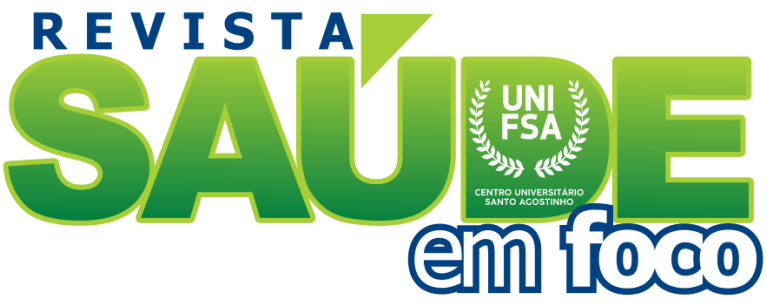

www4.fsanet.com.br/revista

Revista Saúde em Foco, Teresina, v. 7, n. 3, art. 4, p. 49-62, set./dez. 2020

ISSN Eletrônico: 2358-7946

http://dx.doi.org/10.12819/rsf.2020.7.3.4

\title{
Levantamento dos Possíveis Remédios Caseiros Disponíveis na Internet para Tratamento do Coronavírus
}

\section{Survey of Possible Home Remedies Available on the Internet for Coronavirus Treatment}

Maria Adrielly Alves Teixeira

Graduanda em Bacharelado em Farmácia pelo Centro Universitário Santo Agostinho

E-mail: mariaadriellyteixeira@gmail.com

Raimundo Nonato Cardoso Miranda Júnior

Doutor em Biologia de Agentes Infecciosos e Parasitários pela Universidade Federal do Pará Professor do Centro Universitário Santo Agostinho

E-mail: jrfarmaceutico@hotmail.com

Endereço: Maria Adrielly Alves Teixeira

Av. Valter Alencar 665 - São Pedro Teresina - PI - Cep: 64.019-625, Brasil.

Endereço: Raimundo Nonato Cardoso Miranda Júnior

Av. Valter Alencar 665 - São Pedro Teresina - PI - Cep: 64.019-625, Brasil.
Editor-Chefe: Dr. Tonny Kerley de Alencar Rodrigues

Artigo recebido em 12/06/2020. Última versão recebida em 14/07/2021. Aprovado em15/07/2021.

Avaliado pelo sistema Triple Review: a) Desk Review pelo Editor-Chefe; e b) Double Blind Review (avaliação cega por dois avaliadores da área).

Revisão: Gramatical, Normativa e de Formatação 


\title{
RESUMO
}

Com o cenário tenso e acompanhado por muita desinformação, como acontece com outras doenças, como a Dengue, se espalharam pelas redes sociais receitas caseiras ditas milagrosas e que seriam capazes de prevenir ou curar o coronavírus. Mesmo diante do grande avanço da medicina e dos conhecimentos em farmácia nos dias atuais, o consumo de plantas medicinais, com base na tradição familiar, ainda é uma prática generalizada na medicina popular. A respeito das receitas caseiras encontradas na internet, constituídas por gengibre, limão, alho, abacate, erva-doce e gergelim, se consumidas adequadamente, mescladas a uma alimentação saudável, podem até ser benéficas para o sistema imunológico, no entanto não se tem evidências científicas sobre a eficácia desses alimentos contra a COVID-19.

Palavras-chave: Internet. Remédios Caseiros. COVID-19. Fake News.

\begin{abstract}
With the tense scenario and accompanied by a lot of misinformation, as with other diseases, such as Dengue, can spread through social networks homemade recipes of miraculous and that can cause damage or cure the coronavirus. Even with all the great advances in medicine and knowledge in pharmacy today, the consumption of medicinal plants, based on family tradition, is still a widespread practice in popular medicine. Respect for homemade recipes found on the internet, consisting of ginger, lemon, garlic, avocado, fennel and sesame, can consume drinks, mixed and a healthy diet can even be beneficial for the immune system, however, it does not have its benefits scientific evidence on the effectiveness of these foods against a COVID-19.
\end{abstract}

Keywords: Internet. Home Remedies. COVID-19. Fakes News. 


\section{INTRODUÇÃO}

A COVID 19, doença causada pelo coronavírus denominado SARS-CoV-2, foi identificada pela primeira vez na China, em dezembro de 2019. Em 30 de janeiro de 2020, a Organização Mundial da Saúde (OMS) declarou que a epidemia constituía uma Emergência de Saúde Pública de Importância Internacional e, em 11 de março de 2020, tornou-se uma pandemia. Considerando que até o momento não existem evidências científicas robustas que possibilitem a indicação de terapia farmacológica específica para a doença, a falta de informações leva muitas pessoas a realizarem pesquisas na internet em busca de possíveis remédios caseiros, que podem trazer a cura ou aliviar os sintomas (LANA et al., 2020).

Com o cenário tenso e acompanhado por muita desinformação, como acontece com outras doenças, como a Dengue, se espalharam pelas redes sociais receitas caseiras ditas milagrosas e que seriam capazes de prevenir ou curar o coronavírus. Esses ditos "remédios", que não possuem qualquer comprovação científica de sua eficácia, constam em publicações compartilhadas inúmeras vezes na internet e podem induzir pessoas ao erro, inclusive podendo se intoxicar com substâncias que não possuem efeito benéfico ao organismo.

Diversos trabalhos avaliando a automedicação observaram que alguns dos fatores que influenciam os indivíduos a se automedicarem são: a dificuldade de acesso aos serviços de saúde, tanto pela demora quanto pelo preço de uma consulta médica; a limitação do poder prescritivo; a recomendação de medicamentos por conhecidos ou balconistas de farmácias; a repetição de sintomas anteriores, levando o indivíduo a seguir as prescrições já utilizadas; a falta de tempo para procurar um profissional da saúde; a divulgação de medicamentos pela mídia e o livre comércio de medicamentos, passando a imagem de que são produtos inofensivos à saúde (MATOS et al., 2018).

Dentre as dezenas de receitas caseiras de remédios para o coronavírus, os ingredientes mais comuns são: gengibre, álcool, óleo de gergelim, lâmpada ultravioleta, suco de limão, prata coloidal, água com vinagre, alho fervido, chá de boldo, erva-doce, mastruz, jambo, moringa, cebola. Nesse sentido, objetivou-se suscitar reflexões sobre a forma como os remédios caseiros costumam ser veiculados por meio dos websites e redes sociais, que podem ser acessados a qualquer instante, por qualquer pessoa e, através dos quais, diversas recomendações médicas são feridas dando-nos a perceber, dentre outras coisas, que, embora os órgãos competentes estejam desenvolvendo ações e monitoramentos no chamado ciberespaço, existem aspectos que precisam ser abordados no sentido de explicitar quais os 
riscos ou não de certas substâncias ditas eficazes para prevenir e curar os efeitos do COVID 19.

\section{METODOLOGIA}

Trata-se de uma pesquisa integrativa, de caráter qualitativo descritivo. Para a pesquisa, foram consultadas várias literaturas relativas ao assunto, artigos publicados na internet e livros que possibilitaram que este trabalho tomasse forma para ser fundamentado. A pesquisa foi desenvolvida a partir de 20 artigos coletados das bases: Scielo (Scientific Eletronic Library Online), Bireme (Centro Latino-Americano e do Caribe de Informação em Ciências da Saúde) e google acadêmico (https://scholar.google.com.br). Utilizou-se como descritores a receita caseira de remédios para coronavírus, automedicação na internet e combate ao coronavírus. Os critérios de inclusão para os estudos foram artigos completos em língua portuguesa, relacionados ao uso da temática, publicados entre 1990 e 2020, selecionados 15 artigos. Foram excluídos artigos incompletos, de língua estrangeira e artigos que não se encaixavam no tema proposto. Após a coleta de dados, fez-se a leitura de todo o material, posteriormente realizou-se uma análise descritiva, buscando a compreensão e a organização dos resultados para melhor discussão dos dados.

\section{REFERENCIAL TEÓRICO}

\subsection{Remédios Caseiros}

Ao longo da história da vida humana, o homem conseguiu tirar proveito dos recursos naturais. No passar dos anos, argutos observadores repararam que uma erva capaz de induzir sono seria também capaz de acalmar, se usada em dosagens menores. Plantas cujos frutos comumente tinham efeito purgante poderiam ser usadas com certo controle para regular intestino ocioso, toda esta compreensão foi passada oralmente ao longo de gerações que, simultaneamente, com mitos e rituais, constituíram parte elementar das culturas locais (BRASIL, 2019).

Como afirma o conselho regional de farmácia do estado de São Paulo, o uso de plantas para tratamento de enfermidades já se fazia presente nas primeiras civilizações. Em sua cartilha sobre o uso de plantas medicinais e fitoterápicos, afirma que esse costume esteve presente há mais de 5.000 anos, como mostram manuscritos encontrados na China. 
Similarmente ocorreu esta prática nos povos egípcios, cerca de 1.600 a.C., listando muitos medicamentos feitos a partir de plantas, animais e minerais. Na Grécia, Hipócrates (460-377 a.C.), conhecido como o Pai da Medicina, estudou as reações individuais de cada paciente a uma determinada doença e usou os próprios poderes curativos das pessoas. Dessa forma, o tratamento era ajustado ao indivíduo, com dose unitária e personalizada, e incluía dieta, massagem, hidroterapia, repouso e preparações de plantas. No séc. IV a.C., Aristóteles (384 322 a.C.) mantinha um jardim com mais de 300 espécies de ervas (BRASIL, 2019).

Mesmo diante do grande avanço da medicina e dos conhecimentos em farmácia nos dias atuais, o consumo de plantas medicinais, com base na tradição familiar, ainda é uma prática generalizada na medicina popular. Atualmente, muitos fatores têm contribuído para o aumento da utilização desse recurso, entre eles os efeitos colaterais decorrentes do uso crônico dos medicamentos industrializados, o difícil acesso da população à assistência médica, o maior consumo de produtos naturais, bem como a tendência ao uso da medicina integrativa e abordagens holísticas dos conceitos de saúde e bem-estar (MONTEIRO; BRANDELLI, 2017).

\subsection{Automedicação pela internet}

Mesmo sendo uma atitude muito perigosa, a automedicação é uma prática comum no Brasil e no mundo inteiro. Especialmente no período da pandemia do COVID-19, a ingestão de medicamentos por conta própria pode mascarar os sintomas do novo coronavírus, além de que as combinações entre medicamentos também podem ser prejudiciais ao paciente, por conta dos efeitos colaterais, que podem causar a intoxicação e até morte.

A automedicação é toda prática caracterizada sobretudo pela atitude de um adoentado ou de seu responsável, em conseguir ou executar e usufruir de um produto que espera lhe oferecer benefícios na cura da doença ou alívio de sintomas. Assim, a orientação médica é alterada precipitadamente por recomendações de medicamentos oriundos de pessoas não autorizadas, seja entre estas familiares, amigos ou balconistas de farmácias, seja até mesmo, na maioria das situações, através da pesquisa realizada na internet. Levando em conta a comodidade, rapidez e conveniência, obter produtos, realizar pesquisas, bem como poder conversar com amigos e com pessoas desconhecidas através da Internet, sem precisar sair de casa, são algumas das facilidades que tal canal de comunicação informal tem ofertado aos seus usuários (PAULO; ZANINE, 1988). 
Ocorre um pensamento errôneo e reforçado por interesse comercial de que medicamentos sem receita não fazem mal. Mesmo o mais comum dos antiácidos pode provocar reações adversas e, por essa razão, os remédios isentos de prescrição médica não são isentos de riscos. Os fatores mais comuns que motivam a automedicação são dor de cabeça, dor de garganta, gripe e resfriado, entre outros problemas. São utilizados medicamentos de prescrição médica, que deveriam ser adquiridos e utilizados somente com a receita do profissional habilitado. A Organização Mundial de Saúde define que o uso racional de medicamentos ocorre quando "os pacientes recebem a medicação adequada às suas necessidades clínicas, nas doses correspondentes aos seus requisitos individuais, durante um período de tempo adequado e ao menor custo possível para eles e para a comunidade (MARQUES, 2014).

Um levantamento realizado pela consultoria IQVIA, a pedido do Conselho Federal de Farmácia, apontou o aumento significativo nas vendas de medicamentos e vitaminas relacionados à Covid-19 nos primeiros meses do ano de 2020 em relação ao mesmo período do ano 2019. Entre eles, estão o ácido ascórbico (vitamina C), associado por fake news à prevenção da doença, que teve um crescimento de 198,23\%; o paracetamol, com 83,56\% a mais em sua comercialização e a dipirona sódica, com aumento de $51 \%$ como mostra a Figura 1 (CONSELHO FEDERAL DE FARMÁCIA, 2020).

Figura 1 - Impacto do COVID-19 na Venda de Medicamentos.

\begin{tabular}{|c|c|c|c|}
\hline $\begin{array}{c}\text { MEDICAMENTO/PRINCÍPIO } \\
\text { ATIVO }\end{array}$ & $\begin{array}{c}\text { JAN A } \\
\text { MAR/2019 }\end{array}$ & $\begin{array}{c}\text { JAN A } \\
\text { MAR/2020 }\end{array}$ & $\%$ \\
\hline HIDROXICLOROQUINA SULFATO & 231.546 & 388.829 & $67,93 \%$ \\
\hline IBUPROFENO & 15.010 .195 & 14.615 .066 & $-2,63 \%$ \\
\hline PARACETAMOL & 11.150 .452 & 19.774 .819 & $77,35 \%$ \\
\hline DIPIRONA SÓDICA & 30.226 .256 & 46.716 .599 & $54,56 \%$ \\
\hline COLECALCIFEROL (VITAMINA D) & 4.440 .289 & 6.019 .038 & $35,56 \%$ \\
\hline ACIDO ASCÓRBICO (VITAMINA C) & 9.327 .016 & 26.116 .340 & $180,01 \%$ \\
\hline
\end{tabular}

Fonte: CFF (2020).

Mediante esta pesquisa, todos os conselhos de Farmácia atentaram que estes fármacos oferecem riscos. A dipirona propicia risco de choque anafilático e agranulocitose, e o ibuprofeno é associado a tonturas e visão turva. Já o uso prolongado da vitamina $\mathrm{C}$ pode causar disenterias, dores abdominais e de cabeça. O medicamento que oferece mais perigo é a hidroxicloroquina, que também é indicado para tratar doenças como o lúpus eritematoso, 
podendo causar complicações na visão, convulsões, insônia, diarreias, vômitos, alergias graves, arritmias e até parada cardíaca (CONSELHO FEDERAL DE FARMÁCIA, 2020).

\subsection{Coronavírus-COVID 19 e as informações falsas}

Coronavírus são RNA vírus responsáveis por infecções respiratórias em uma variedade de animais, abrangendo aves e mamíferos. Sete coronavírus são caracterizados como patógenos na população, os coronavírus sazonais estão em geral ligados a síndromes gripais. Nos últimos 20 anos, dois deles foram causadores de epidemias mais virulentas de síndrome respiratória aguda grave (SRAG). A epidemia de SARS, que emergiu em Hong Kong (China), em 2003, com mortalidade de aproximadamente $10 \%$ e a síndrome respiratória do Oriente Médio (MERS) que emergiu na Arábia Saudita em 2012 com letalidade de cerca de $30 \%$. Ambos fazem parte da lista de doenças prioritárias para pesquisa e desenvolvimento no contexto de emergência (LANA et al., 2020).

Em casos de situação emergencial na área de saúde, como surtos, epidemias e pandemias, a comunicação é essencial e a informação precisa dos fatos auxilia os órgãos responsáveis a tomarem medidas mais eficazes (BRASIL, 2020a). Porém, a evolução da comunicação ao longo das décadas e a facilidade de acesso, consumo, divulgação, criação e compartilhamento de informações proporcionada pelas mídias sociais começaram a trazer implicações não somente para o ambiente on-line como também para a realidade global, por exemplo, com a popularização das notícias falsas, as chamadas Fake News (SOUSA JÚNIOR; PETROLL; ROCHA, 2019).

Paralelamente à propagação do novo coronavírus, o Sars-CoV-2, a Organização Mundial da Saúde (OMS) chamou a atenção para outro tipo de surto que também apresenta risco potencial à saúde pública e foi batizado por ela de infodemia. Trata-se da difusão massiva de desinformação, mentiras e rumores sobre a pandemia, comprometendo o acesso a dados com respaldo de cientistas e autoridades sanitárias. Além das notícias falsas, hoje conhecidas como fake news, o crescimento vertiginoso no volume de informações nem sempre precisas, divulgadas diariamente pelos meios de comunicação, também podem desnortear as pessoas (PIERRO, 2020).

O combate à desinformação é reforçado pelas universidades e instituições de pesquisa. A Universidade Johns Hopkins, nos Estados Unidos, criou um hotsite. Nele, reúne dados atualizados em tempo real sobre casos confirmados de Covid-19 no mundo, incluindo número de mortes e pacientes que se recuperaram da doença. É possível acessar um mapa on-line, que 
permite visualizar casos confirmados por país, entre outras informações regionais. A Universidade Federal de Minas Gerais (UFMG) também criou uma página especialmente para divulgar informações sobre o novo coronavírus. Foi organizada uma lista com links para acessar o site de órgãos como a Organização Pan-americana da Saúde e a OMS. Há também notícias de interesse da comunidade interna da universidade, como iniciativas de ensino a distância para os alunos. A Fundação Oswaldo Cruz (Fiocruz), por sua vez, lançou um aplicativo chamado "Eu fiscalizo", que permite aos usuários avaliar conteúdos veiculados nos meios de comunicação, referentes não só ao novo coronavírus, mas a assuntos de saúde pública em geral (PIERRO, 2020).

Mediante a grave situação, percebe-se um movimento acelerado por conquista de informações que ajudem o combate eficiente contra o coronavírus. Esse movimento é produto de um sistema de vigilância internacional sensível, assim como de uma política de compartilhamento de dados e achados. Enquanto alguns grupos rapidamente se organizaram para monitorar casos em tempo real, outros se empenharam na aplicação de modelos matemáticos e estatísticos para monitorar o novo vírus e definir estratégias de ação. Em contraste, o avanço do uso de mídias sociais como meio de informação trouxe consigo o desafio de responder rapidamente a conteúdos falsos, disseminados nesses canais, e de forma que possam igualmente circular neles. Por exemplo, em paralelo às notícias oficiais e matérias informativas em veículos tradicionais, áudios falsos com recomendações equivocadas circularam em mídias sociais se passando por comunicado de entidades de respaldo público como a Sociedade Brasileira de Infectologia (SBI). Também houve a tentativa de resgatar o mito de que certos chás têm as mesmas propriedades antivirais do fosfato de oseltamivir (princípio ativo do antiviral usado para o tratamento de SRAG por vírus Influenza), sugerindo o consumo destes para casos de influenza e coronavírus. Posteriormente, por meio de notas de esclarecimento por parte da SBI e do Ministério da Saúde, essas informações foram desmentidas, mas, infelizmente, não se sabe ao certo se essa informação obteve o mesmo alcance das notícias falsas. Diante desses acontecimentos, percebe-se crescente movimento de descrédito dos canais tradicionais de comunicação, que fomentam a adesão a fontes alternativas, torna-se também um risco à saúde pública que deve ser enfrentado. A comunicação de especialistas não pode ficar restrita ao ambiente acadêmico e a profissionais da área (LANA et al., 2020 p:3). 


\section{RESULTADOS E DISCUSSÃO}

No Brasil, o Ministério da Saúde criou uma página especial para combater fake news sobre a Covid-19. A pasta disponibilizou um número de WhatsApp (61 99289-4640), para que a população envie fatos duvidosos veiculados nas mídias sociais e aplicativos de mensagens, para serem checados por uma equipe técnica do ministério. No site, as informações são classificadas em duas listas, de acordo com os selos "Isto é fake news" ou "Esta notícia é verdadeira" como mostra a Figura 2. Também são reunidos dados sobre prevenção, transmissão do vírus e atendimento pelo Sistema Único de Saúde (SUS) e é possível acessar um podcast sobre a pandemia, produzido pelo próprio ministério (PIERRO, 2020).

Figura 2 - Fake News Combatida Pelo Ministério da Saúde Brasileiro.

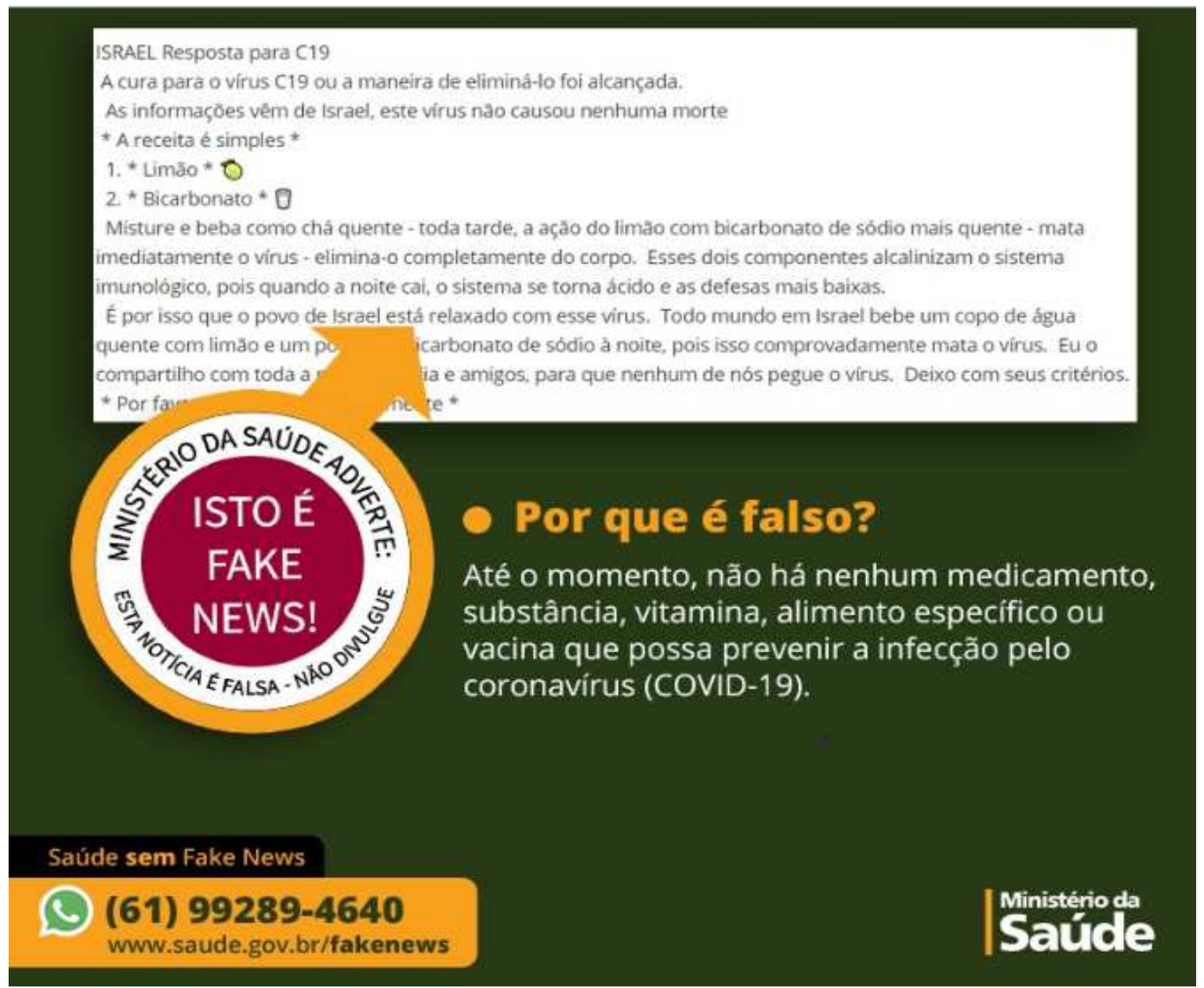

Fonte: BRASIL ( 2020b) 
As redes sociais estão repletas de receitas caseiras que prometem proteger e eliminar o coronavírus. $\mathrm{Na}$ ausência de recursos médicos suficientes para toda a população e o desconhecimento imediato da própria medicina do tratamento para o COVID-19, muitas pessoas tendem a recorrer a meios de acesso mais fácil para atender a suas necessidades, foi o que se efetuou no período da pandemia do coronavírus, várias dicas e informações compartilhadas na internet, principalmente em redes sociais, de prática e manipulações de vegetais e substâncias diversas, que em algumas situações podem até trazer riscos à saúde humana. Neste estudo, separaram-se 10 receitas caseiras mais veiculadas em redes e mídias sociais, listadas no Quadro 1, apresentando seu modo de preparo e seus possíveis benefícios.

\begin{tabular}{|c|c|}
\hline $\begin{array}{l}\text { REMÉDIOS CASEIROS } \\
\text { COMPARTILHADOS NA } \\
\text { INTERNET }\end{array}$ & PREPARO E CONSUMO \\
\hline Gengibre & $\begin{array}{l}\text { Consumido puro ou cozido. Segundo a receita compartilhada nas } \\
\text { redes sociais, é necessário ficar } 24 \text { horas em jejum para que ela possa } \\
\text { fazer o efeito desejado, que é o aumento da temperatura corporal. }\end{array}$ \\
\hline Prata & $\begin{array}{l}\text { Receita envolve uma solução feita de prata que, supostamente, o } \\
\text { metal nobre consegue fortalecer o seu sistema imunológico e matar } \\
\text { vários tipos diferentes de vírus. }\end{array}$ \\
\hline Óleo de gergelim & O óleo tem poder de matar o COVID-19 ao ser ingerido no corpo. \\
\hline Lâmpadas ultravioleta & $\begin{array}{l}\text { Lâmpadas UV são utilizadas para esterilizar mãos ou outras áreas da } \\
\text { pele, pois a radiação UV mata o vírus. }\end{array}$ \\
\hline Chá de limão & $\begin{array}{l}\text { Segundo a publicação, basta beber uma infusão de limão com dois } \\
\text { dentes de alho, algumas folhas e a flor de jambu, planta comum na } \\
\text { região Norte do Brasil, para sentir alívio nos sintomas e ficar curado. }\end{array}$ \\
\hline $\begin{array}{l}\text { Vitamina de abacate com } \\
\text { hortelã }\end{array}$ & O seu consumo diário inibe a contaminação do vírus \\
\hline Uísque com mel & $\begin{array}{l}\text { Esta receita de uísque quente e mel blindaria o corpo contra a } \\
\text { infecção, o álcool presente na bebida seria o responsável pela } \\
\text { proteção }\end{array}$ \\
\hline Alho e água quente & $\begin{array}{l}\text { Sua composição traz oito dentes de alho e sete xícaras de água. Após } \\
\text { ferver, basta consumir para ficar curado "da noite para o dia" }\end{array}$ \\
\hline Vinagre & $\begin{array}{l}\text { Esta informação foi vinculada em um vídeo afirmando que vinagre é } \\
\text { mais eficiente que álcool gel na proteção contra o novo coronavírus }\end{array}$ \\
\hline Chá de erva doce & $\begin{array}{l}\text { Previne a infecção do COVID-19, porque tem a mesma } \\
\text { substância que o remédio Tamiflu, utilizado para tratar gripe e } \\
\text { deve ser consumido de } 12 \text { em } 12 \text { horas ou após as refeições. }\end{array}$ \\
\hline
\end{tabular}

Fonte: Autor (2020).

É importante ressaltar que até o início do mês de junho de 2020 não se tinha comprovado existência de algum medicamento, substância, vitamina, alimento específico ou vacina que pudesse prevenir a infecção pelo coronavírus (COVID-19). Órgãos competentes, 
a exemplo disso o Ministério Saúde (BR), combateram incansavelmente todas as informações falsas conhecidas como FAKE NEWS, de modo a esclarecer o maior número de pessoas possível de que todas essas 10 indicações listadas no Quadro 1 foram desmentidas e não possuem qualquer comprovação científica de sua eficácia, presentes em publicações compartilhadas inúmeras vezes na internet, induzindo as pessoas ao erro, inclusive podendo até intoxicar com substâncias que não possuem efeito benéfico ao organismo. Além do portal especializado no esclarecimento das Fake News sobre o Coronavírus, o Ministério da Saúde também criou um alerta nas principais redes sociais virtuais que aciona uma mensagem alertando para conteúdos relevantes e informações verdadeiras sempre que alguém busca o termo "coronavírus", como pode ser observado na Figura 3.

Figura 3- Alerta do Ministério da Saúde do Brasil como combate às Fake News nas redes sociais

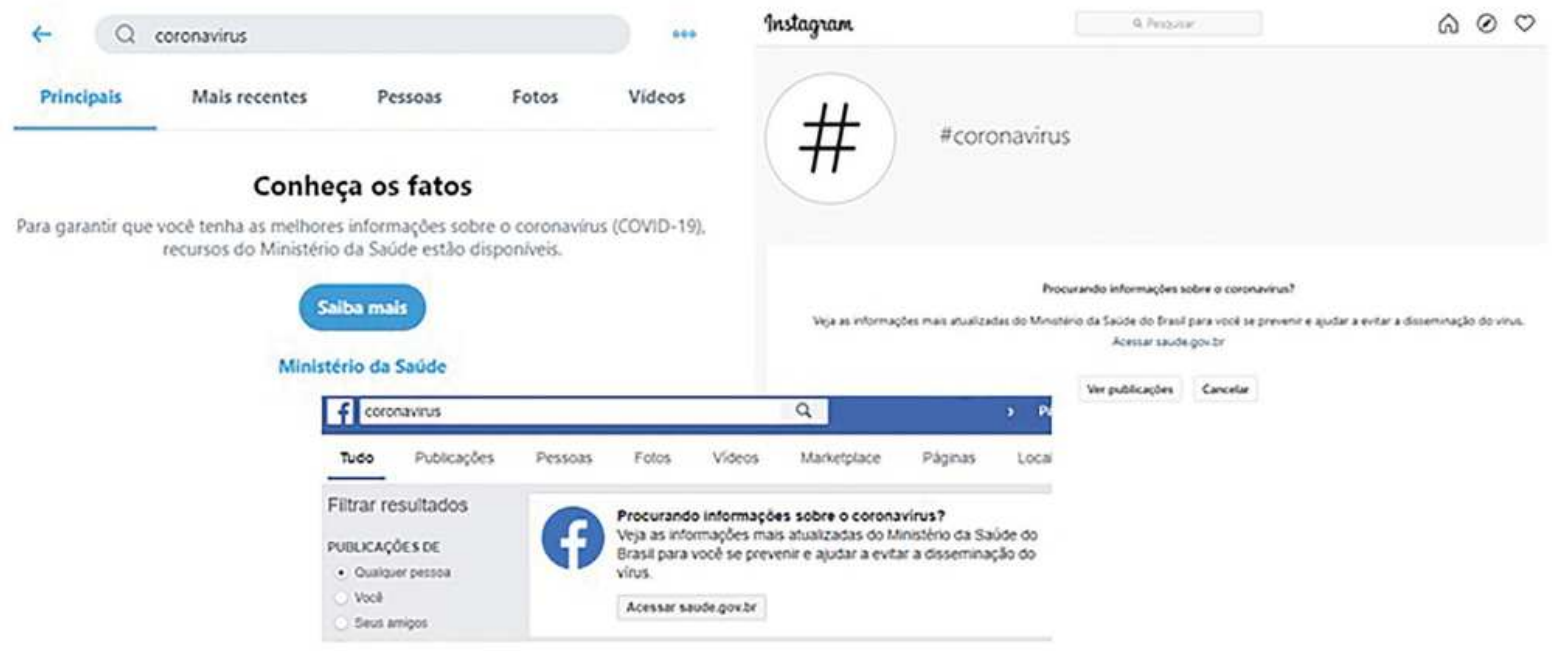

Fonte: Coletados nas ferramentas de busca do Facebook, Instagram e Twitter (2020)

Como afirma Neto et al., (2020), Fake News são informações/notícias/postagens concebidas de forma duvidosa que, sem a devida averiguação, levam o leitor a pseudoinformações. Estas informações geralmente usam uma linguagem possível de entendimento voltada para os leigos no campo da pesquisa ou para leitores desavisados. Em muitos casos são ultizados nomes de autoridades da área do conhecimento articulados às instituições de pesquisa renomadas. 
Quadro 2 - Exemplos de Fake News, segundo o Banco de Dados do Ministério da Saúde (BR).

\begin{tabular}{|c|c|c|c|}
\hline Categoria & Título da Notícia & $\begin{array}{l}\text { Veículo de } \\
\text { informação }\end{array}$ & Contra-argumentação \\
\hline $\begin{array}{c}\text { Informações relacionadas } \\
\text { aos discursos de } \\
\text { autoridades na saúde }\end{array}$ & $\begin{array}{l}\text { Aplicativo Coronavírus- } \\
\text { SUS, do Governo do } \\
\text { Brasil, é inseguro }\end{array}$ & WhatsApp & $\begin{array}{l}\text { O aplicativo Coronavírus-SUS- } \\
\text { COVID-19 foi desenvolvido pelo } \\
\text { Ministério da Saúde, com as } \\
\text { precauções de segurança em sua } \\
\text { construção e na divulgação das } \\
\text { informações. }\end{array}$ \\
\hline Terapêutica & $\begin{array}{l}\text { Tomar bebidas quentes } \\
\text { para matar o coronavírus }\end{array}$ & WhatsApp & 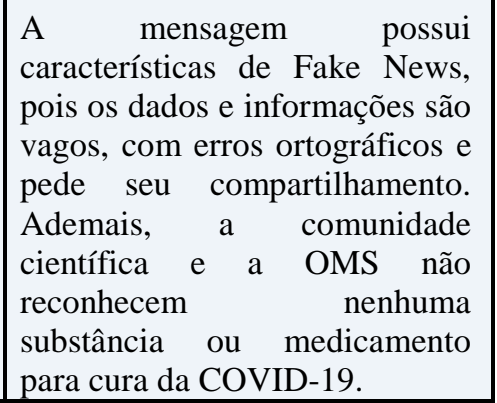 \\
\hline Medida de prevenção & $\begin{array}{c}\text { Beber muita água e fazer } \\
\text { gargarejo com água } \\
\text { morna, } \\
\text { sal e vinagre previnem } \\
\text { coronavírus }\end{array}$ & WhatsApp & $\begin{array}{l}\text { Até o momento, não há } \\
\text { evidência de nenhum } \\
\text { medicamento, substância, } \\
\text { vitamina, alimento, muito } \\
\text { menos beber muita água e fazer } \\
\text { gargarejo com estas substâncias } \\
\text { para prevenir a infecção pelo } \\
\text { coronavírus (COVID-19). }\end{array}$ \\
\hline Prognósticos da doença & $\begin{array}{l}\text { Pesquisa publicada por } \\
\text { cientistas chineses diz que } \\
\text { coronavírus tornará a } \\
\text { maioria dos pacientes do } \\
\text { sexo masculino infértil }\end{array}$ & Internet & $\begin{array}{l}\text { O artigo citado está em fase de } \\
\text { pré- publicação e não foi revisado } \\
\text { pelos pares, portanto tem pouco } \\
\text { valor científico no momento. Esse } \\
\text { artigo traz dados preliminares } \\
\text { sobre a possibilidade de infecção } \\
\text { de células do testículo pelo } \\
\text { coronavírus (COVID-19), porém } \\
\text { menciona que não existem dados } \\
\text { suficientes para se estabelecer um } \\
\text { risco de esterilidade masculina. }\end{array}$ \\
\hline Vacinação & $\begin{array}{c}\text { China anuncia vacina para } \\
\text { coronavírus }\end{array}$ & Internet & $\begin{array}{l}\text { Não há vacina contra o } \\
\text { coronavírus até o momento, } \\
\text { apesar de haver pesquisas em } \\
\text { andamento. }\end{array}$ \\
\hline
\end{tabular}

Fonte: BRASIL, 2020

Em uma pesquisa realizada por Neto et al., (2020), na busca das notícias Fake News, através do banco de dados do Ministério da Saúde, verificando a disseminação de notícias falsas no cenário da pandemia de COVID-19, no período de 29 de janeiro a 31 de março de 2020, foram identificados 70 registros. Estes, após a coleta de dados, foram repassados a uma tabela elaborada pelos autores, para organização das informações como a data de publicação, título da notícia, veículo de informação e síntese dos registros. Os exemplos apontados no Quadro 2 apontam, por meio de amostragem aleatória, a divulgação de informações 
consumidas que rodaram nas redes sociais pelo compartilhamento de Fake News e como foram freadas pelo Ministério da Saúde.

\section{CONSIDERAÇÕES FINAIS}

A respeito das receitas caseiras encontras na internet, constituídas por gengibre, limão, alho, abacate, erva-doce e gergelim, se consumidas adequadamente, mescladas a uma alimentação saudável, podem até ser benéficas para o sistema imunológico, no entanto não se tem evidências científicas sobre a eficácia desses alimentos contra a COVID-19, já as receitas que utilizam prata, uísque e lâmpadas ultravioleta oferecem um grande risco à saúde humana, podendo intoxicar e agravar o quadro de paciente positivo para coronavírus. A literatura brasileira ainda é muito escassa de informações sobre a pandemia de COVID-19 e percebe-se que a velocidade desta produção do conhecimento necessita alcançar o ritmo da produção das Fake News. Enfatiza-se, ainda, a necessidade de a população conhecer o site do Ministério da Saúde brasileiro, o qual aponta as Fake News, para que ocorra educação em saúde com informações corretas e seguras.

\section{REFERÊNCIAS}

BRASIL. Ministério da Saúde. 2020b. Disponível em: http://www.saude.gov.br/. Acesso em: 20 mar. 2020.

Ministério da Saúde (BR). Secretaria de Vigilância em Saúde. Boletim Epidemiológico. Infecção humana pelo novo coronavírus (2019-nCoV). [Internet]. Brasília: Ministério da Saúde; 2020a [acesso em 08 de junho 2020].Disponível em: https://portalarquivos2.saude.gov.br/images/pdf/2020/fevereiro/07/BE-COECoronavirus-n020702.pdf.

. Ministério da Saúde (BR). Saúde sem Fake News, 2018. [acesso em 08 junho 2020]. Disponível em: https://www.saude.gov.br/fakenews.

CONSELHO FEDERAL DE FARMÁCIA. Levantamento mostra como o medo da COVID-19 impactou venda de medicamentos, 2020. (Pode ser acessado em: http://www.cff.org.br/noticia.php?id=5747 ).

LANA, R. M. et al. The novel coronavirus (SARS-CoV-2) emergency and the role of timely and effective national health surveillance. Cadernos de Saude Publica, v. 36, n. 3, 2020.

MARQUES, T. R. Fatores associados à automedicação factors associated with medication. 2014.

MATOS, J. F. et al. Prevalência, perfil e fatores associados à automedicação em adolescentes e servidores de uma escola pública profissionalizante. Cadernos Saúde Coletiva, v. 26, n. 1, p. 76-83, 2018. 
NETO, M. et al. Fake news no cenário da pandemia de covid-19. Cogitare Enfermagem, v. $25,2020$.

MONTEIRO, S. C.; BRANDELli, C. L. C. Farmacobotânica: Aspectos Teóricos e Aplicação. Porto Alegre - Artmed, 2017.

PAUlO, L. G; ZANINE A. C. Automedicação no Brasil. Rev. Ass. Med. Bras., 34: 69-75, 1988.

PIERRO. D. B. Epidemia-de-fake-News. revistapesquisa.fapesp.br. 2020

SOUSA JÚNIOR, J. H.; PETROLL, M. D. L. M.; ROCHA, R. A. Fake News e o Comportamento Online dos Eleitores nas Redes Sociais durante a Campanha Presidencial Brasileira de 2018. In: XXII SEMEAD - SEMINÁRIOS EM ADMINISTRAÇÃO, USP, São Paulo, 2019. Anais [...], São Paulo, 2019.

\section{Como Referenciar este Artigo, conforme ABNT:}

TEIXEIRA, M. A. A; MIRANDA JÚNIOR, R. N. C. Levantamento dos Possíveis Remédios Caseiros Disponíveis na Internet para Tratamento do Coronavírus. Rev. Saúde em Foco, Teresina, v. 7, n. 3, art. 4, p. 49-62, set./dez.2020.

\begin{tabular}{|l|c|c|}
\hline \multicolumn{1}{|c|}{ Contribuição dos Autores } & $\begin{array}{l}\text { M. A. A. } \\
\text { Teixeira }\end{array}$ & $\begin{array}{l}\text { R. N. C. } \\
\text { Miranda } \\
\text { Júnior }\end{array}$ \\
\hline 1) concepção e planejamento. & $\mathrm{X}$ & $\mathrm{X}$ \\
\hline 2) análise e interpretação dos dados. & $\mathrm{X}$ & $\mathrm{X}$ \\
\hline 3) elaboração do rascunho ou na revisão crítica do conteúdo. & $\mathrm{X}$ & $\mathrm{X}$ \\
\hline 4) participação na aprovação da versão final do manuscrito. & $\mathrm{X}$ & $\mathrm{X}$ \\
\hline
\end{tabular}

